Invited paper

\title{
Identification of sources of polycyclic aromatic hydrocarbons based on concentrations in soils from two sides of the Himalayas between China and Nepal ${ }^{\text {is }}$
}

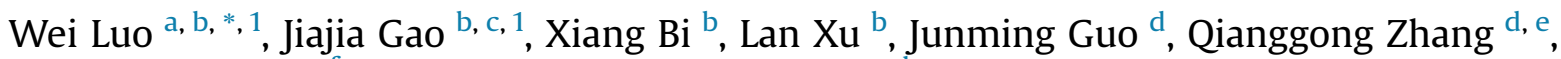 \\ Kumar Y. Romesh ${ }^{\mathrm{f}}$, John P. Giesy ${ }^{\mathrm{g}}$, Shichang Kang ${ }^{\mathrm{h}, \mathrm{e}}$ \\ ${ }^{a}$ College of Life and Environmental Science, Minzu University of China, Beijing, 100081, China \\ b State Key Laboratory of Urban and Regional Ecology, Research Center for Eco-Environmental Sciences, Chinese Academy of Sciences, Beijing, 100085, China \\ ${ }^{\mathrm{c}}$ Tibet Climatic Center, Lhasa, 850001, China \\ ${ }^{\mathrm{d}}$ Key Laboratory of Tibetan Environment Changes and Land Surface Processes, Institute of Tibetan Plateau Research, Chinese Academy of Sciences (CAS), \\ Beijing, 100085, China \\ e CAS Center for Excellence in Tibetan Plateau Earth Sciences, Chinese Academy of Sciences, Beijing, 100101, China \\ ${ }^{\mathrm{f}}$ Department of Environmental Science and Engineering, School of Science, Kathmandu University, Kathmandu, 6250, Nepal \\ ${ }^{g}$ Department of Veterinary Biomedical Sciences and Toxicology Centre, University of Saskatchewan, Saskatoon, Canada \\ h State Key Laboratory of Cryospheric Sciences, Cold and Arid Regions Environmental and Engineering Research Institute, Chinese Academy of Sciences, \\ Lanzhou, 730000, China
}

\section{A R T I C L E I N F O}

\section{Article history:}

Received 2 March 2015

Received in revised form

9 November 2015

Accepted 13 November 2015

Available online 21 February 2016

\section{Keywords:}

Polycyclic aromatic hydrocarbons

Tibetan Plateau

Indian monsoon

South Asia

Atmospheric transport

\begin{abstract}
A B S T R A C T
To understand distribution and sources of polycyclic aromatic hydrocarbons (PAHs) in the Himalayas, 77 soil samples were collected from the northern side of the Himalayas, China (NSHC), and the southern side of the Himalayas, Nepal (SSHN), based on altitude, land use and possible trans-boundary transport of PAHs driven by wind from Nepal to the Tibetan Plateau, China. Soils from the SSHN had mean PAH concentration greater than those from the NSHC. Greater concentrations of PAHs in soils were mainly distributed near main roads and agricultural and urban areas. PAHs with 2-3 rings were the most abundant PAHs in the soils from the Himalayas. Concentrations of volatile PAHs were significantly and positively correlated with altitude. Simulations of trajectories of air masses indicated that distributions of soil PAH concentrations were associated with the cyclic patterns of the monsoon. PAH emissions from traffic and combustion of biomass or coal greatly contributed to concentrations of PAHs in soils from the Himalayas.
\end{abstract}

() 2015 Elsevier Ltd. All rights reserved.

\section{Introduction}

Due to atmospheric and temperature gradients, distributions of polycyclic aromatic hydrocarbons (PAHs) are dependent on the altitude. This phenomenon has been described as the "altitude effect". The transport of PAHs to remote areas and their fates have received increasing attention in the last decade (Wania and Mackay, 1996). Long-Range Atmospheric Transport (LRAT) is

\footnotetext{
This paper has been recommended for acceptance by Jay Gan.

* Corresponding author. State Key Laboratory of Urban and Regional Ecology, Research Center for Eco-Environmental Sciences, Chinese Academy of Sciences, Beijing, 100085, China.

E-mail address: luow@rcees.ac.cn (W. Luo).

1 Jiajia Gao and Wei Luo contributed equally to this work.
}

driven by wind, deposition and air-soil exchange, which are the most important global transport pathways for PAHs and the most important processes governing their global distribution.

High mountains are similar to the Arctic in terms of their lower temperatures, ice cover, remoteness, and ecological community structures that vary along altitudinal gradients. PAH distributions change along altitudinal gradients in these regions and are governed by the relative proximity to emission sources, local meteorological conditions and ecological gradients (Tremolada et al., 2008). The Himalayas have large variations in altitude, including Mt. Everest, which is the highest mountain in the world with an altitude of $8848 \mathrm{~m}$. The Tibetan Plateau, China (TPC) is on northern side of the Himalayas and is referred to as the "Roof of the World" or the "Earth's Third Pole". The Himalayas have a cold and harsh climate, and they might act as cold traps for airborne semi-volatile 
contaminants such as PAHs (Dachs et al., 1999). Meanwhile, due to the comparatively small human population, the Himalayas are remote from modern industrial and commercial activities (Loewen et al., 2005). Therefore, the Himalayas are regarded as an ideal site for studying regional and global atmospheric circulation of PAHs (Wang et al., 2014). However, despite the unique geography and climate of the Himalayas, emissions of PAHs from adjacent countries such as Nepal and India are estimated to be much greater than those within the TPC, which potentially has an influence on the environment and ecosystems of the Himalayas and even the TPC (Zhang and Tao, 2009).

In recent years, the LRAT of PAHs has been studied in remote mountainous regions (Elliott et al., 2012; Aichner et al., 2007). The main source of PAHs in the mountains is deposition from the atmosphere (Wang et al., 2007). Soil plays an important role in the global fate and distribution of PAHs. Due to its large capacity to retain hydrophobic compounds, it has been identified as an effective reservoir/sink of PAHs in terrestrial environments (Bhatt and Sachan, 2004; Wang et al., 2014). Furthermore, it has to be regarded as a long-term archive of the atmospheric deposition rather than an indicator of the actual inputs. Studies of the Himalayas have indicated that PAHs emitted in Nepal and India may be transported by the Southern Asian monsoon along valleys from the Indian Subcontinent to the Himalayas (Kang et al., 2009). It has been reported that concentrations of PAHs in soils of Nepal (184-10,279 ng/g, dry weight (dw)) (Aichner et al., 2007) were greater than those reported in northern slope of the CentralHimalayas on the TPC (5.5-62.2 ng/g, dw) (Wang et al., 2014). The concentration of PAHs in soils might pose risks to the ecosystem of the Himalayas, which is also an important source of freshwater for as much as one sixth of the world's population (including China, India and Nepal) (Loewen et al., 2005). Therefore, it is important not only to know the spatial distribution of the concentrations, pathways (sources), and potential health effects of PAHs in the soils on both sides of the Himalayas between China and Nepal but also to understand the cross-border migration and spatial variability of atmospheric deposition of PAHs between South Asia and the most pristine and remote areas of the TPC. However, so far, no large-scale investigation of concentrations of PAHs in soils from both sides of the Himalayas between China and Nepal has been conducted.

This study aimed to determine the PAH concentrations and distributions in top soils from two sides of the Himalayas and identify the sources and the factors influencing their distributions, such as wind direction, altitude and land use. This study not only evaluated the possibility of PAH transport from Nepal and India to the TPC but also provided essential information for future studies of long-range transport and the cold trap effects of PAHs and their risks to human health.

\section{Materials and methods}

\subsection{Study area}

The Himalayas separate the TPC, from southeast Asian countries, including Nepal and India (Fig. 1A), and consist of a series of parallel and converging ranges covering an area of approximately $6 \times 10^{5} \mathrm{~km}^{2}$. The climate system of the Himalayas between Nepal and China includes two parts, namely the Indian Monsoon system (from June to September) and the southern branch of the westerly winds (from November to March) (Wang et al., 2010). In the summer, the low pressure in this region drives air masses over India to the Himalayas, which normally results in significant precipitation. The distinct seasonal differences in wind direction and regional and orographic precipitation may be important for the atmospheric

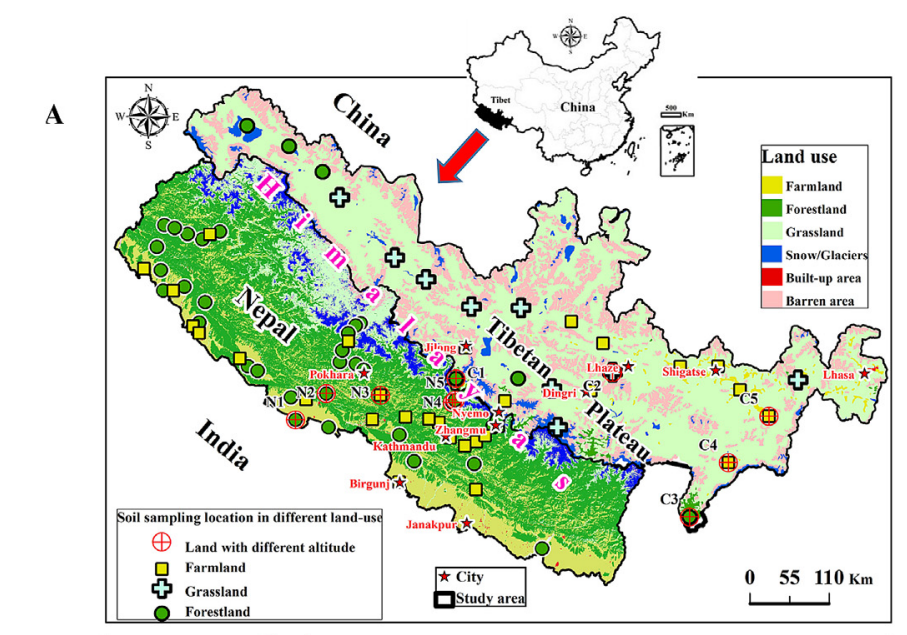

B

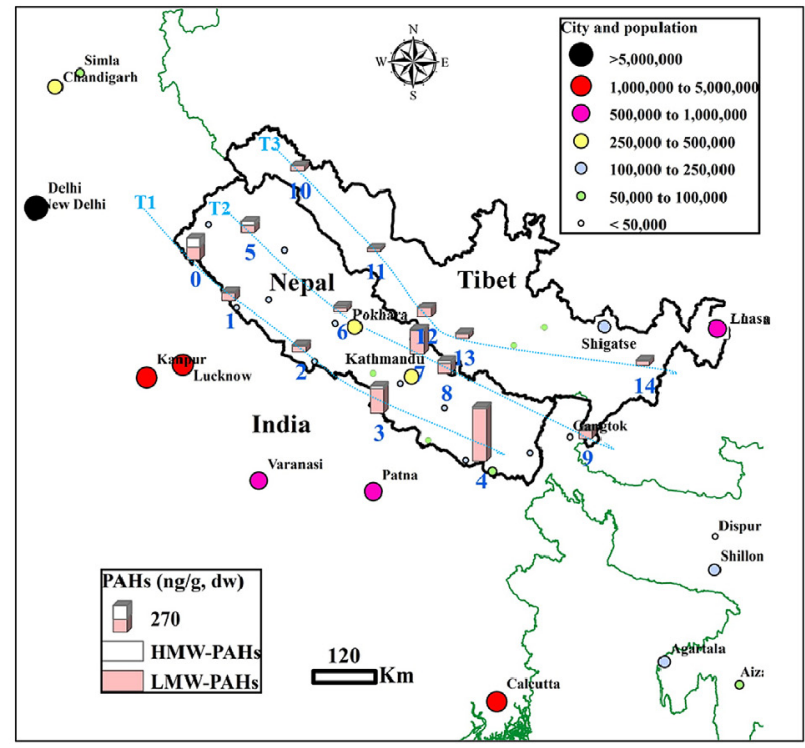

Fig. 1. Soil sampling locations from different land uses (A) and three transects (B) on the northern and southern sides of the Himalayas between China and Nepal. Distribution of LMW- and HMW-PAHs and total concentrations of PAHs are also given.

transport and deposition of compounds in this area. Several important cities and counties, including Dingri, Jilong, Nyemo, Shigatse City (the largest Chinese city in the study area), Kathmandu City (capital of Nepal), Pokhara and Birgunj (in Nepal) are located in the study area (Fig. 1A).

\subsection{Soil sampling and chemical analysis}

From June 2013 to March 2014, seventy-seven soil samples were collected from the Himalayan Mountains in China and Nepal based on land use, wind direction and altitude in the study area (Fig. 1A, B). In total, 30, 9 and 38 soil samples were collected from farm-, grass- and forest-lands, respectively, at altitudes of $45-5242 \mathrm{~m}$ (Table 4). Of the 77 soil samples, 50 were collected from the southern side of the Himalayas, Nepal (SSHN) at altitudes of 45-2763 $\mathrm{m}$ and the rest from the northern side of the Himalayas, China (NSHC) at altitudes of 1623-5242 m (Table 1).

To determine effects of wind on concentrations of PAHs, fifteen soil samples were collected from three transects. Along each transect, there was almost no local human activity, and the altitudes of the transect sites were approximately the same (Fig. 1B). Transect 1 (T1) had five numbered sites (marked 0-4) which were distributed 
Table 1

Descriptive statistics for concentrations of PAHs in soils from the northern to southern sides of the Himalayas between China and Nepal (ng/g, dw).

\begin{tabular}{|c|c|c|c|c|c|c|c|c|c|}
\hline & \multicolumn{3}{|c|}{ China $(\mathrm{n}=27)$} & \multicolumn{3}{|c|}{ Nepal $(\mathrm{n}=50)$} & \multirow{2}{*}{$\frac{\text { Transect } 1(\mathrm{n}=5)}{\text { Mean } \pm \text { Sd }}$} & \multirow{2}{*}{$\frac{\text { Transect } \mathrm{T} 2(\mathrm{n}=5)}{\text { Mean } \pm \mathrm{Sd}}$} & \multirow{2}{*}{$\frac{\text { Transect T3 }(\mathrm{n}=5)}{\text { Mean } \pm \mathrm{Sd}}$} \\
\hline & Min & Max & Mean \pm Sd & Min & Max & Mean \pm Sd & & & \\
\hline Altitude (unit: m) & 1623 & 5242 & $4187 \pm 815$ & 45 & 2763 & $778 \pm 700$ & $107 \pm 48$ & $1681 \pm 640$ & $4535 \pm 412$ \\
\hline Naphthalene (Nap) & $\mathrm{BDL}^{\mathrm{a}}$ & 5.3 & $1.5 \pm 1.7$ & $\mathrm{BDL}$ & 195 & $34 \pm 34$ & $37 \pm 11$ & $18 \pm 19$ & $7.9 \pm 11$ \\
\hline Acenaphthylene (Acy) & 0.54 & 35 & $31 \pm 32$ & 0.17 & 364 & $43 \pm 89$ & $38 \pm 58$ & $23 \pm 29$ & $4.3 \pm 7.6$ \\
\hline Acenaphthene (Ace) & 0.06 & 39 & $12 \pm 10$ & 0.13 & 28 & $5.1 \pm 6.1$ & $6.5 \pm 7.5$ & $13 \pm 11$ & $6.7 \pm 3.9$ \\
\hline Fluorene $(\mathrm{Fl})$ & 0.63 & 94 & $26 \pm 24$ & 0.16 & 246 & $53 \pm 74$ & $79 \pm 104$ & $24 \pm 30$ & $13 \pm 14$ \\
\hline Phenanthrene (Phe) & 0.08 & 96 & $28 \pm 22$ & 0.11 & 93 & $30 \pm 18$ & $45 \pm 334$ & $23 \pm 8.1$ & $180 \pm 13$ \\
\hline Anthracene (An) & 0.90 & 72 & $6.2 \pm 14$ & 0.40 & 18 & $3.9 \pm 4.4$ & $3.6 \pm 3.1$ & $4.3 \pm 4.4$ & $2.7 \pm 2.4$ \\
\hline Fluoranthene (Flu) & BDL & 15 & $3.9 \pm 3.7$ & BDL & 33 & $7.5 \pm 7.8$ & $14 \pm 12$ & $5.2 \pm 2.7$ & $0.37 \pm 0.44$ \\
\hline Pyrene (Pyr) & BDL & 16 & $3.4 \pm 3.9$ & 0.05 & 18 & $4.8 \pm 4.1$ & $5.7 \pm 6.2$ & $4.8 \pm 1.8$ & $0.87 \pm 0.68$ \\
\hline Benzo(a)anthracene (BaA) & BDL & 4 & $0.25 \pm 0.92$ & BDL & 6.4 & $1 \pm 1.6$ & $1.4 \pm 2.5$ & $0.48 \pm 0.70$ & $\mathrm{BDL}$ \\
\hline Chrysene (Chr) & BDL & 62 & $3.0 \pm 14$ & BDL & 10 & $2.1 \pm 2.6$ & $2.6 \pm 4.3$ & $1.2 \pm 2.0$ & BDL \\
\hline Benzo(b)fluoranthene (BbF) & 0.04 & 4.1 & $0.84 \pm 1.1$ & BDL & 12 & $2.4 \pm 2.6$ & $3.2 \pm 4.7$ & $2.0 \pm 2.8$ & $0.80 \pm 0.90$ \\
\hline Benzo(k)fluoranthene (BkF) & BDL & 6.4 & $0.86 \pm 1.6$ & BDL & 9.5 & $1.7 \pm 2.2$ & $2.64 \pm 3.9$ & $1.5 \pm 2.4$ & $0.40 \pm 0.50$ \\
\hline Benzo(a)pyrene (BaP) & BDL & 17 & $1.9 \pm 4.2$ & BDL & 3.7 & $0.81 \pm 0.95$ & $1.2 \pm 1.3$ & $3.9 \pm 7.1$ & $1.7 \pm 2.3$ \\
\hline Indeno(1,2,3-cd)pyrene (InP) & BDL & 0.47 & $0.14 \pm 0.11$ & BDL & 3.6 & $0.78 \pm 0.9$ & $1.0 \pm 1.5$ & $1.0 \pm 1.5$ & $\mathrm{BDL}$ \\
\hline Dibenzo(a,h)anthracene (DBA) & BDL & 0.29 & $0.12 \pm 0.11$ & BDL & 0.54 & $0.14 \pm 0.12$ & $0.20 \pm 0.2$ & $0.10 \pm 0.10$ & $0.10 \pm 0.10$ \\
\hline Benzo(g,hi)perylene (BghiP) & BDL & 99 & $5.5 \pm 21$ & 0.11 & 3.9 & $0.99 \pm 0.84$ & $1.1 \pm 1.2$ & $1.8 \pm 1.8$ & $0.25 \pm 0.50$ \\
\hline$\sum 2-3$ ring $\mathrm{PAHs}$ & 2.3 & 303 & $109 \pm 107$ & 5.6 & 793 & $168 \pm 194$ & $209 \pm 195$ & $106 \pm 79$ & $53 \pm 23$ \\
\hline$\sum 4-6$ ring PAHs & 0.040 & 24 & $17 \pm 47$ & 0.35 & 64 & $22 \pm 20$ & $33 \pm 34$ & $22 \pm 14$ & $5.0 \pm 3.7$ \\
\hline$\sum 16 \mathrm{PAHs}$ & 2.3 & 327 & $126 \pm 83$ & 6.0 & 800 & $190 \pm 192$ & $242 \pm 193$ & $128 \pm 76$ & $58 \pm 22$ \\
\hline
\end{tabular}

a Below detection level.

along the boundary between Nepal and India. T1 was designed to monitor the influence of the wind from the lower altitude Indian Plain. Transect 2 (T2) had five numbered sites (marked 5-9) which were located along the boundary between Nepal and China and on the southern side of the Himalayas in Nepal. T2 was selected to measure the influence of wind from both Nepal and India. Transect 3 (T3) had five numbered sites (marked 10-14) which were positioned along the north side of the Himalayas on the TPC (Fig. 1B). T3 was designed to measure effects of the Himalayas on transport of PAHs in masses of air from southern Asian countries. To trace the possible origins of the PAHs, backward air mass trajectories were calculated for fifteen sites where the fifteen soils were collected in study area. Five-day back-trajectories of air masses were computed using the Hybrid Single-Particle Lagrangian Integrated Trajectory (HYSPLIT) model at $1000 \mathrm{~m}$ (a commonly used height for HYSPLIT) above ground level at $6 \mathrm{~h}$ intervals from June 2013 to March 2014 (Figs. S1 and S2).

To explore the relationship between concentrations of PAHs in soil and altitude on the regional scale, 10 samples ( $\mathrm{C} 1-\mathrm{C} 5$ in China and N1-N5 in Nepal) were collected at different altitudes in the study area (Fig. 1A). As suggested by Wang et al. (2014), these lands should be far from towns, roads or other human activities.

Each soil sample consisted of a composite of subsamples collected from the top $5 \mathrm{~cm}$ of soil at five sites using a stainless steel shovel. These subsamples were combined to obtain a representative sample before being sealed in a clean plastic bag.

After air drying, soils were ground or crushed, passed through 2$\mathrm{mm}$ mesh sieves, spiked with a surrogate standard mixture (Naphthalene-d8 (Nap-d8), acenaphthene-d10 (Acp-d10), phenanthrene-d10 (Phe-d10), chrysene-d12 (Chr-d12) and perylene-d12 (Per-d12)) and extracted by accelerated solvent extraction with mixed solvents (hexane/dichloromethane, 1:1, v/v). After rotary evaporation concentration, extracts were cleaned-up using a Florisil silica column. An Agilent 7890 gas chromatograph (GC) with a J\&W HP-5 ms capillary column $(30 \mathrm{~m} \times 0.25 \mathrm{~mm}$ i.d $\times 0.25 \mu \mathrm{m}$ ) was used for separation and an Agilent 5975 mass spectrometer (MS) with an electrospray ionization source was used for detection. The MS was operated in selective ion monitoring mode to detect 16 indicator PAHs specified by US Environmental Protection Agency, i.e., Naphthalene (Nap), acenaphthylene (Acy), acenaphthene (Ace), fluorene (Fl), phenanthrene (Phe), anthracene
(An), fluoranthene (Flu), pyrene (Pyr), benzo[a]anthracene (BaA), chrysene (Chr), benzo[b]fluoranthene $(\mathrm{BbF})$, benzo[k]fluoranthene (BkF), benzo[a]pyrene (BaP), indeno[1,2,3-cd]pyrene (InP), dibenzo [a,h]anthracene (DBA) and benzo[g,h,i]perylene (BghiP). A detailed description of the chemical analysis of PAHs in soil is provided by Yang et al. (2013). The concentration of soil organic carbon (SOC) was measured using a TOC analyser (Shimadzu 5000-A, Japan). The soil $\mathrm{pH}$ was measured using the potentiometric method with a 5:1 water:soil ratio.

\subsection{Quality assurance/Quality control}

Procedural blanks were measured with each set of ten samples to test for interference, cross-contamination and stability of the instrument during the entire analytical process. The dominant $\mathrm{PAH}$ congener was Nap in the procedural blanks, and the mean concentration was $1.2 \mathrm{ng} / \mathrm{g}$, dw, which was much less than concentrations in the samples. All concentrations were corrected by subtraction of the concentration in the procedural and recoveries of surrogates. The method detection limits (MDLs) based on a signalto-noise ratio of 3 in real samples ranged from 0.04 to $0.72 \mathrm{ng} / \mathrm{g}$, dw for individual PAHs. The analytical procedure was successfully calibrated using a standard reference material with certificated concentrations of PAHs (New Haven, CT). Mean recoveries of spiked surrogates were $88 \%-97 \%$. Replicate analysis of soils gave an error $\leq \pm 10 \%$. Performance of the instrument was routinely checked by use of quality control standards.

\subsection{Statistical analyses}

Data were analysed for homogeneity of variance and normality. In cases in which total concentrations of PAHs ( $\left.\Sigma_{16} \mathrm{PAHs}\right)$ in soils from China and Nepal were normally distributed, Student's t-test was used to detect differences between paired means. In cases in which the normality test failed, the Mann-Whitney nonparametric test was conducted. Principle component analyses (PCA) are commonly used to extract valuable information from multivariate sets of data. By utilizing the orthogonal transformation method, principle components (PCs) are extracted with different factor loadings that indicate the correlations of each pollutant species with each PC. Each PC was further evaluated and recognized 
by source markers or profiles for likely sources of PAHs (Harrison et al., 1996). In the present study, PCA with varimax rotation was performed, using SPSS 20.0 (Chicago, IL) software. A spatial analysis was conducted using the software ArcGIS 10.0 for Windows (Gamma Design, 1994), for concentrations of 16 PAHs in 50 soil samples from Nepal and 27 soil samples from China, respectively.

\section{Results and discussion}

\subsection{Concentrations of PAHs in soil}

Concentrations of $\Sigma_{16}$ PAHs in soils from the NSHC ranged from 2.3 to $327 \mathrm{ng} / \mathrm{g}$, dw (Table 1 ), with a mean ( \pm standard deviation (sd)) of $126 \pm 83 \mathrm{ng} / \mathrm{g}$, dw. The mean value was greater than background concentrations of $\Sigma_{16}$ PAHs in the TPC soils ( $52 \pm 39 \mathrm{ng} /$ $\mathrm{g}, \mathrm{dw}$ ) reported by Tao et al. (2011), who investigated 88 surface soils from the Qinghai-TPC (Table 2). In the present study, the mean concentration of $\Sigma_{16} \mathrm{PAHs}$ was greater than those previously reported in East, Middle, West and Northwest regions of the Tibetan Plateau on the NSHC (Qi et al., 2003; Wang et al., 2008, 2013; Tao et al., 2011; Yuan et al., 2015), but less than those observed in the town of Gaize, the area surrounding Mt. Qomolangma and Southeast TPC, and mountainous areas in Europe, Australia and Canada (Choi et al., 2009; van Drooge et al., 2011; Yang et al., 2013; Yuan et al., 2014) (Table 2).

Concentrations of $\Sigma 2-3$-ring PAHs (low molecular weight PAHs (LMW-PAHs)) in soils from the NSHC ranged from 2.3 to $303 \mathrm{ng} / \mathrm{g}$, $\mathrm{dw}$, with a mean \pm sd of $109 \pm 107 \mathrm{ng} / \mathrm{g}$, dw. This accounted for $87 \%$ of the mean concentration of total PAHs (Table 1). Acy and Phe were the most abundant 2-3-ring PAHs. The mean concentrations of Acy and Phe in soils from the NSHC were 31 and $28 \mathrm{ng} / \mathrm{g}$, dw, which accounted for $25 \%$ and $23 \%$ of the mean concentration of total PAHs, respectively (Table 1 ). This result is consistent with results reported by Wang et al. (2007). However, 27\% of the soil samples from the NSHC had concentrations of Phe that were significantly greater than the maximum permissible concentration of $50 \mathrm{ng} / \mathrm{g}$, dw, suggested by the Netherlands. Although the mean concentration of toxic PAHs ( $\geq 4$-ring PAHs) only accounted for $13 \%$ of the mean concentrations of total PAHs (Table 1), their potential risks to the soil ecosystems on the northern side of the Himalayas, China could not be neglected.

Concentrations of $\Sigma_{16} \mathrm{PAHs}$ in the soils from the SSHN, varied from 6 to $800 \mathrm{ng} / \mathrm{g}$, dw (Table 1). The mean \pm sd concentration of PAHs $(190 \pm 192 \mathrm{ng} / \mathrm{g}$, dw $)$ in the soils from the SSHN was significantly greater than that in the soils from natural areas without human activity, such as Sagarmatha Nation Park, which approaches Mt. Everest, Nepal (Fig. 2), but less than those in the soils from areas with intense human activities, such as the parks, gardens, forests and urban areas in Nepal and India and the southeast area of the TPC (Table 2).

Concentrations of $\Sigma 2-3$-ring PAHs in the soils from the SSHN, ranged from 5.6 to $793 \mathrm{ng} / \mathrm{g}$, dw, with a mean \pm sd of $168 \pm 194 \mathrm{ng} /$ $\mathrm{g}$, dw, which accounted for $88 \%$ of the mean concentration of total PAHs (Table 1). Concentrations of PAHs in the soils were dominated

Table 2

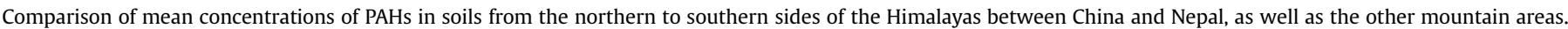

\begin{tabular}{|c|c|c|c|c|c|}
\hline Country & Location & Land use & $\begin{array}{l}\text { Sampling } \\
\text { size }\end{array}$ & PAHs (ng/g, dw) & Reference \\
\hline \multirow[t]{9}{*}{ China } & Northern side of the Himalayas & Forestry, agriculture and pastoral area & 27 & $126 \pm 83^{a}$ & This study \\
\hline & $\begin{array}{l}\text { West and Northwest Tibetan Plateau } \\
\text { (background level) }\end{array}$ & No-man's land and pastoral area & 88 & $52 \pm 39^{a}$ & Tao et al. (2011) \\
\hline & Middle Tibetan Plateau & $\begin{array}{l}\text { Mountain shrubby steppe soils and alpine } \\
\text { steppe soils }\end{array}$ & 44 & $9.2(0.43-26.66)$ & Yuan et al. (2015) \\
\hline & East Tibetan Plateau & Grassland & 35 & $56.26 \pm 45.84$ & Wang et al. (2013) \\
\hline & Southeast Tibetan & Forest & 30 & $201 \pm 126^{a}$ & Yang et al. (2013) \\
\hline & Mt. Xixabangma & Core land & - & $(8.9-97)^{\mathrm{b}}$ & Wang et al. (2008) \\
\hline & Lhala wetland in Lhasa & Wetland & 4 & 83 & Qi et al. (2003) \\
\hline & Gaize town & Desert & 27 & $(1450-12,700)^{\mathrm{b}}$ & Yuan et al. (2014) \\
\hline & Mt. Qomolangma & Grassland & - & $(168-595)^{\mathrm{b}}$ & Wang et al. (2007) \\
\hline \multirow[t]{4}{*}{ Nepal } & Southern side of the Himalayas & Forestry and agriculture & 50 & $190 \pm 192^{\mathrm{a}}$ & This study \\
\hline & Sagarmatha Nation Park & Forestry, agriculture and dwarf shrubs & 12 & $6.4 \pm 2.6^{\mathrm{a}}$ & $\begin{array}{l}\text { Guzzella et al. } \\
\text { (2011) }\end{array}$ \\
\hline & Kathmandu & Park & 5 & 1168 & Aichner et al. (2007) \\
\hline & Kathmandu & Garden & 3 & 457 & Aichner et al. (2007) \\
\hline \multirow[t]{7}{*}{ India } & Kurukshetra & Urban soil & - & $(386-876)^{b}$ & Kumar et al. (2013) \\
\hline & Agra of Taj Mahal & Semi-arid region soil & 320 & $\begin{array}{l}12,100(3100 \\
-28,000)\end{array}$ & $\begin{array}{l}\text { Masih and Taneja, } \\
2006\end{array}$ \\
\hline & Agra of Taj Mahal & Agricultural soil & 80 & 6730 & $\begin{array}{l}\text { Masih and Taneja, } \\
2006\end{array}$ \\
\hline & Agra of Taj Mahal & Industry soil & 80 & 13,720 & $\begin{array}{l}\text { Masih and Taneja, } \\
2006\end{array}$ \\
\hline & Agra of Taj Mahal & Residential soil & 80 & 9370 & $\begin{array}{l}\text { Masih and Taneja, } \\
2006\end{array}$ \\
\hline & Agra of Taj Mahal & Roadside soil & 80 & 12,980 & $\begin{array}{l}\text { Masih and Taneja, } \\
2006\end{array}$ \\
\hline & Delhi (background) & Forest & - & $(511-694)^{\mathrm{b}}$ & Ray et al. (2012) \\
\hline \multirow[t]{6}{*}{$\begin{array}{l}\text { Other mountain } \\
\text { areas }\end{array}$} & Alpine, Europe & Forest & 27 & $(576-9771)^{\mathrm{b}}$ & $\begin{array}{l}\text { van Drooge et al. } \\
\text { (2011) }\end{array}$ \\
\hline & Montseny & Mountain area & 4 & $1475(1000-2100)$ & Quiroz et al. (2011) \\
\hline & Pyrenees Mountain, Europe & Lake catchment areas & 1 & 770 & Grimalt et al. (2004) \\
\hline & Tartra Mountains, Europe & Lake catchment areas & 1 & 1900 & Grimalt et al. (2004) \\
\hline & The Alps, Austria & Forest & 25 & $210(68-1342)^{\mathrm{b}}$ & Weiss et al. (2000) \\
\hline & Mountains in west of Canada & Forest & 22 & $167(2-789)^{\mathrm{b}}$ & Choi et al. (2009) \\
\hline
\end{tabular}

\footnotetext{
- Not available.

a Mean \pm Sd.

b Data in brackets indicates the range of PAHs in soil.
} 


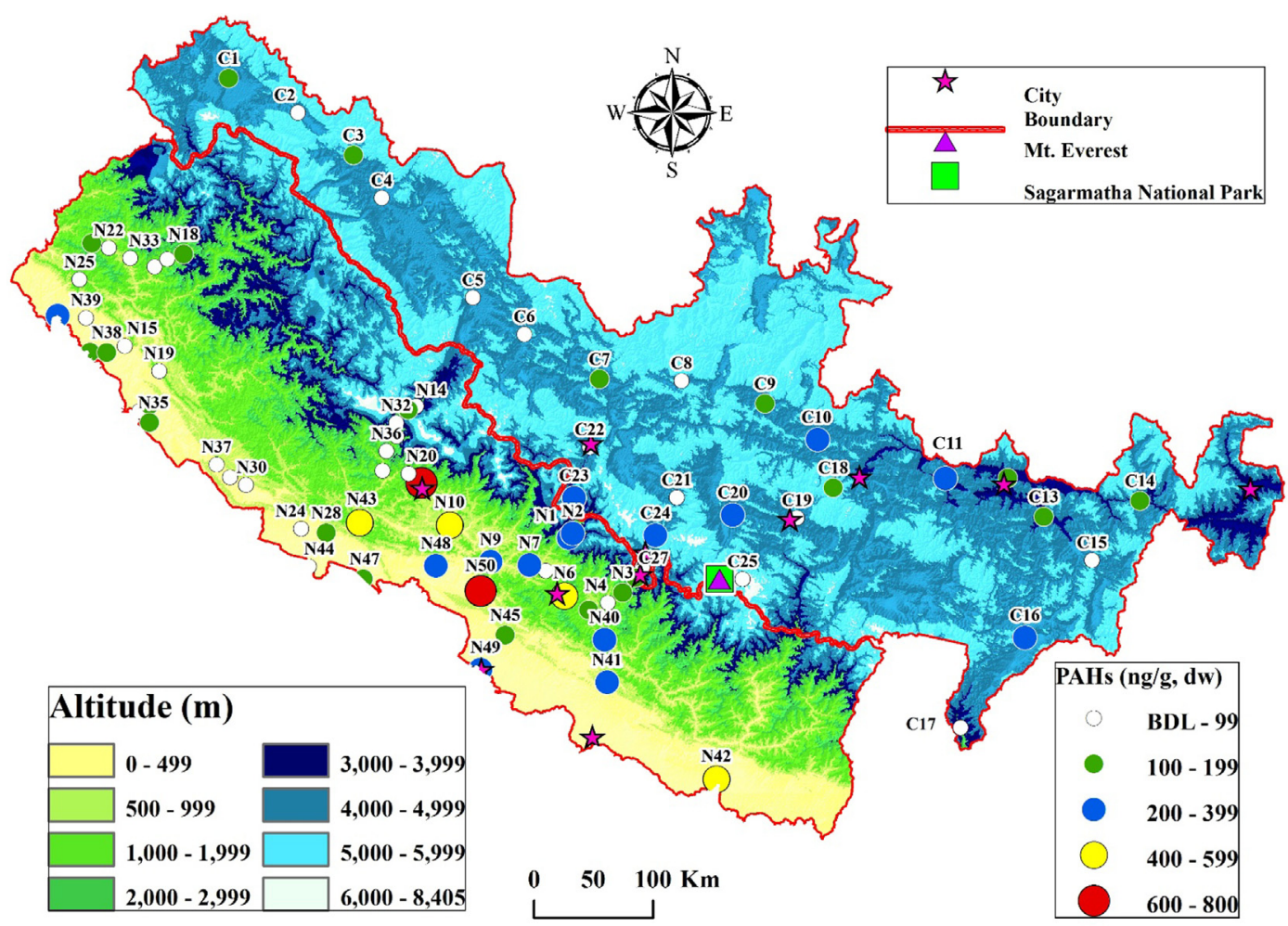

Fig. 2. Spatial distribution of concentrations of PAHs in soils from the northern and southern sides of the Himalayas between China and Nepal.

by 2-3-ring PAHs, especially $\mathrm{Fl}$ and Acy. Mean concentrations of $\mathrm{Fl}$ and Acy in the soils were 53 and $43 \mathrm{ng} / \mathrm{g}$, dw, which accounted for $29 \%$ and $22 \%$ of the mean concentration of total PAHs, respectively (Table 1). This result differed from that reported by Guzzella et al. (2011), who found Phe and Pyr to be dominants in soils of Sagarmatha Nation Park of Nepal.

The mean concentration of PAHs in soils from the SSHN, was significantly greater than that in the soils from the NSHC (T test; $p<0.05)$. Furthermore, according to a soil classification of contamination by PAHs proposed by Maliszewska-Kordybach (1996), $4 \%$ and $32 \%$ of the soils from the SSHN, were contaminated and weakly contaminated, respectively, whereas only $22 \%$ of soil samples from the NSHC, were weakly contaminated by PAHs.

\subsection{Spatial distribution of PAHs in soils and possible sources}

Concentrations of PAHs in soils on the NSHC, were relatively great (200-400 ng/g, dw) at locations C10, C11, C16, C20 and C24, which are located near the important cities and counties such as Shigatse, Lhaze, Dingri, Nyemo (especially Zhangmu port) in the east and middle regions on the NSHC (Fig. 2). Lesser concentrations of $\Sigma_{16} \mathrm{PAHs}$ ( $<200 \mathrm{ng} / \mathrm{g}$, dw) were observed in soils from the west of the NSHC (Fig. 2). In that area there are almost no cities or human activities. The greatest concentration of PAHs in soils $(327 \mathrm{ng} / \mathrm{g}, \mathrm{dw})$ was found at C11 near the urban area of Shigatse, while the least (2.3 ng/g, dw) was observed at C25 near Mt. Everest (Table 1 and Fig. 2).

For the soils in China, four PCs were extracted and explained 84\% of the total variance when PCs with eigenvalues greater than 1 were retained. PC1 explained $37 \%$ of the total variance and had larger loadings on BghiP, Chr, BaA, An and Pyr (Table 3 and Fig. 4). Based on previous studies (Masclet et al., 1986), BghiP and Chr likely resulted from exhausts from diesel vehicles, BaA from burning biomass, and An and Pyr from coal combustion. Therefore, PC1 was
Table 3

Component pattern matrix for varimax rotated PCA analysis of concentrations of 16 PAHs in soils from the northern and southern sides of the Himalayas between China and Nepal.

\begin{tabular}{|c|c|c|c|c|c|c|c|}
\hline \multirow[t]{3}{*}{ Variable } & \multicolumn{7}{|c|}{ Component } \\
\hline & \multicolumn{4}{|l|}{ China } & \multicolumn{3}{|l|}{ Nepal } \\
\hline & 1 & 2 & 3 & 4 & 1 & 2 & 3 \\
\hline Acy & 0.09 & 0.52 & -0.54 & -0.019 & -0.075 & -0.045 & 0.97 \\
\hline Ace & -0.1 & 0.71 & -0.35 & 0.37 & -0.16 & -0.025 & 0.85 \\
\hline $\mathrm{Fl}$ & -0.063 & 0.8 & -0.39 & -0.062 & -0.29 & 0.11 & 0.88 \\
\hline Phe & -0.12 & 0.81 & 0.17 & -0.11 & -0.093 & 0.79 & 0.38 \\
\hline An & 0.96 & 0.02 & 0.15 & 0.057 & -0.21 & 0.07 & 0.3 \\
\hline Flu & 0.4 & 0.76 & 0.23 & 0.14 & 0.19 & 0.96 & 0.024 \\
\hline Pyr & 0.67 & 0.58 & 0.061 & 0.28 & 0.29 & 0.89 & 0.1 \\
\hline $\mathrm{BaA}$ & 0.97 & 0.014 & 0.13 & -0.008 & 0.47 & 0.79 & -0.24 \\
\hline Chr & 0.98 & -0.022 & 0.15 & -0.022 & 0.56 & 0.72 & -0.3 \\
\hline $\mathrm{BbF}$ & 0.49 & 0 & 0.79 & -0.074 & 0.78 & 0.55 & -0.27 \\
\hline $\mathrm{BkF}$ & 0.18 & 0.15 & 0.097 & -0.089 & 0.77 & 0.56 & -0.27 \\
\hline $\mathrm{BaP}$ & -0.089 & 0.12 & 0.86 & -0.072 & 0.89 & 0.27 & -0.16 \\
\hline InP & 0.48 & -0.13 & -0.41 & 0.63 & 0.89 & 0.22 & -0.19 \\
\hline DBA & -0.098 & 0.21 & -0.81 & 0.95 & 0.56 & 0.67 & 0.11 \\
\hline BghiP & 0.98 & -0.021 & 0.13 & -0.031 & 0.93 & 0.14 & 0.11 \\
\hline$\%$ of Variance & 50 & 30 & 12 & 6.7 & 50 & 22 & 10 \\
\hline Cumulative \% & 37 & 60 & 73 & 84 & 30 & 59 & 82 \\
\hline
\end{tabular}

Extraction method: Principal Component Analysis.

regarded as a combined source resulting from traffic emissions and combustion of biomass or coal. PC2 explained 23\% of the total variance and had larger loadings on Phe, Fl, Flu and Ace (Table 3 and Fig. 4). Because Phe, Fl, Flu and Ace are key indicators of coal or wood combustion (Daisey et al., 1986; Harrison et al., 1996; Wilcke and Amelung, 2000), this factor could be related to the combustion of coal or wood. Both PC3 and PC4 explained 24\% of the total variance and had larger loadings on BaP, BbF and DBA (Table 3 and Fig. 4), which originated from vehicle emissions (Daisey et al., 

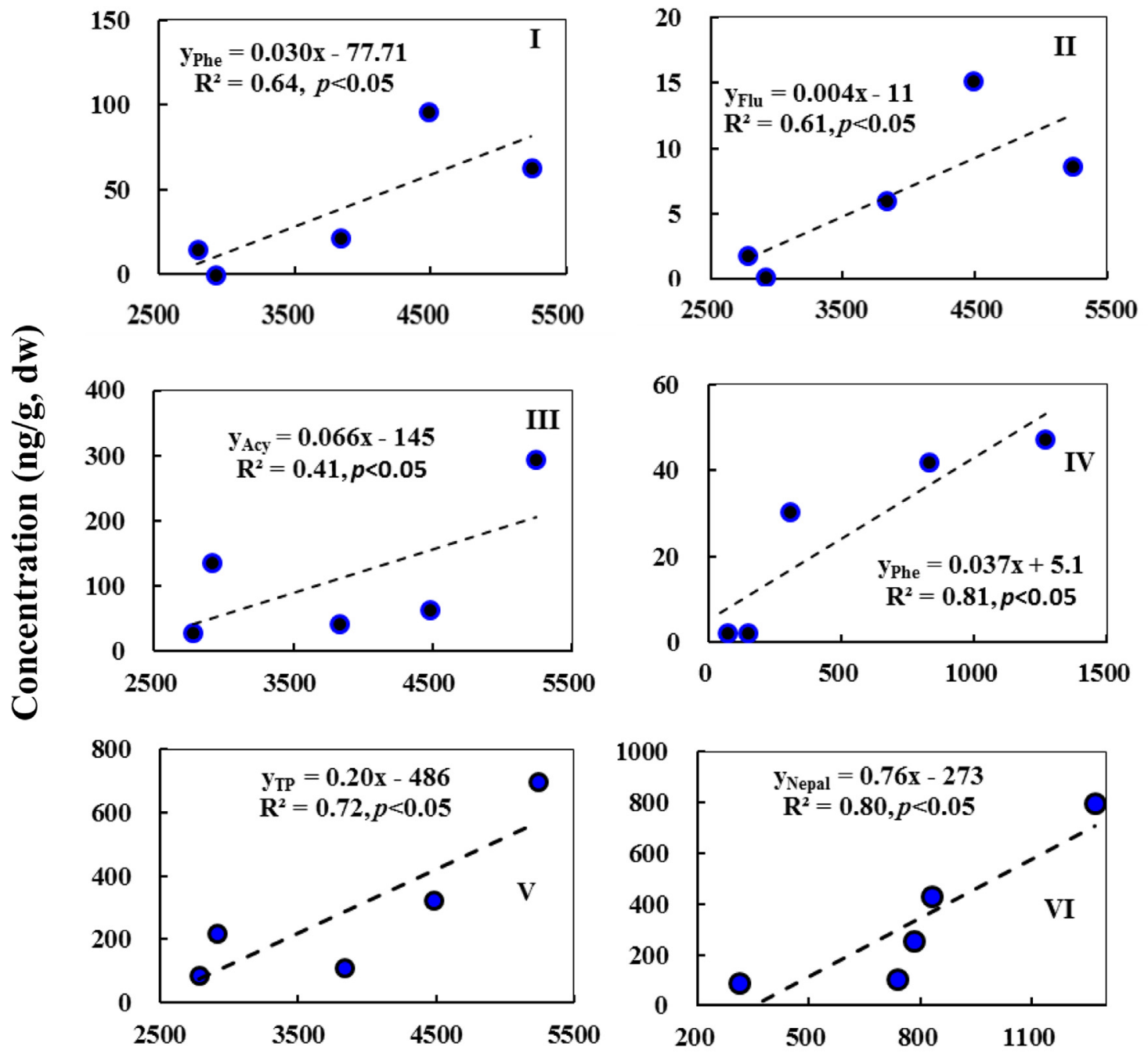

\section{Altitude (m)}

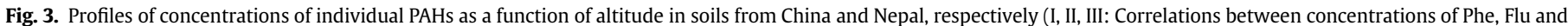

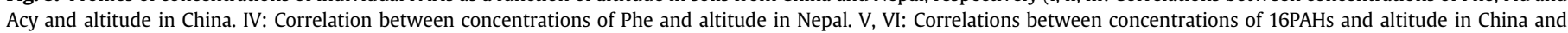
Nepal).
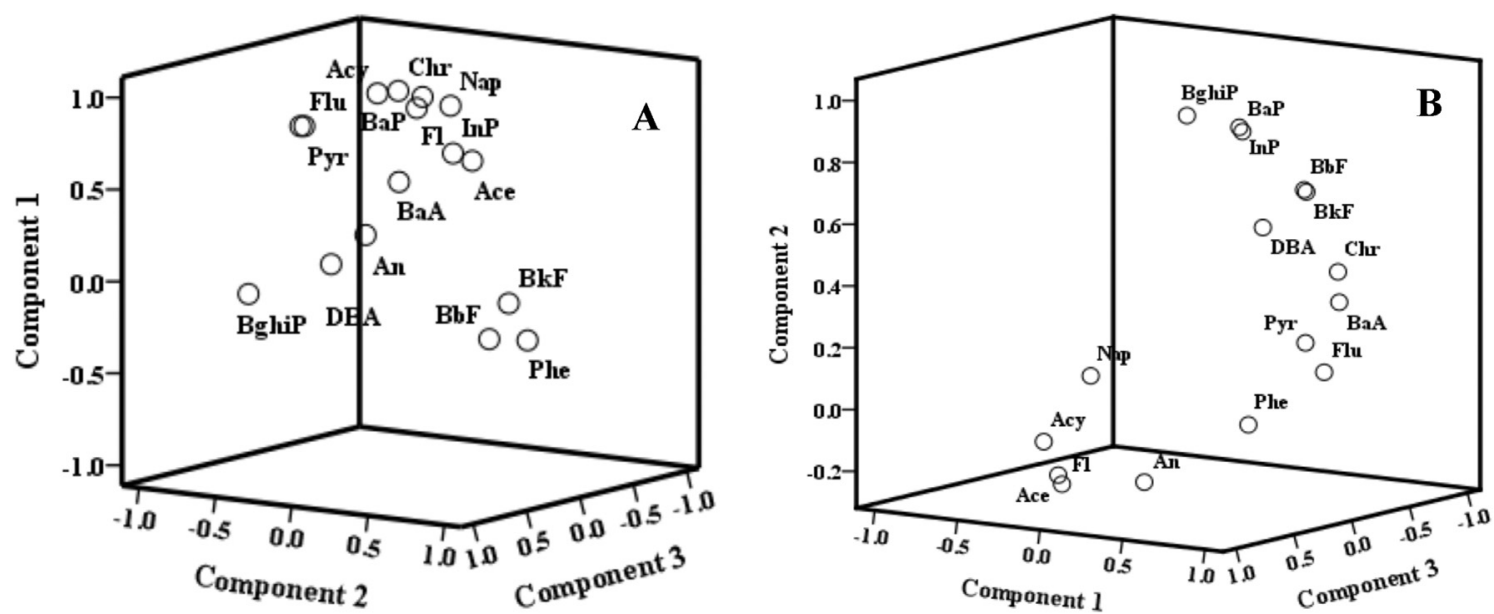

Fig. 4. Molecular load diagrams. Component pattern matrix for varimax rotated PCA analysis of concentrations of 16 PAHs in China (A) and in Nepal (B). 
1986). Flu/(Flu + Pyr) ratios between 0.4 and 0.5 were related to combustion of liquid fossil fuels (Yunker et al., 2002). Because the soils that have relatively great concentrations of PAHs contained $\mathrm{BaP}, \mathrm{BbF}$ and DBA as well as Flu/(Flu + Pyr) ratios of $0.45-0.49$, a major source of PAHs in these soils was from combustion of gasoline in internal combustion engines. This conclusion was further supported by the fact that the soils with high concentrations of PAHs were found along busy national main roads (G219 and G218) which connected the large city of Shigatse with the counties of Lhaze, Dingri and Nyemo and key entry- and exit-port between China and Nepal (Zhangmu) in the study area (Wang et al., 2006).

On the SSHN, the greatest concentration of PAHs in soils (800 ng/g, dw) was found at Pokhara (N11), while the least concentration $(6 \mathrm{ng} / \mathrm{g}, \mathrm{dw})$ was observed at $\mathrm{N} 44$, which was near the southern border of Nepal with India (Table 1 and Fig. 2). According to the system for classifying pollution of soils by PAHs, proposed by Maliszewska-Kordybach (1996), highly contaminated soils (600-1000 ng/g, dw) were found at Pokhara and Birgunj, while weakly contaminated soils (200-600 ng/g, dw) were mainly distributed in the western, central and eastern Nepal, where the important Nepalese cities, such as Kathmandu, Pokhara, Birgunj and Janakpur, are located (Fig. 2). Soils uncontaminated by PAHs were observed in the far-western and mid-western Nepal, which are undeveloped and affected by less human activity (Figs. 1 and 2).

For soils in Nepal, three PCs were extracted, which explained $83 \%$ of the total variance (Table 3 and Fig. 4). PC1 explained $30 \%$ of the total variance and had larger loadings on BghiP, InP and BaP (Table 3), which are considered as high molecular weight PAHs (HMW-PAHs) and released during the incomplete combustion of liquid fossil fuels such as gasoline and diesel fuel (Nakata et al., 2014). The incomplete combustion of fossil fuels results in high levels of PAH deposition, as indicated by $\mathrm{BaA} / \mathrm{BghiP}$ ratios greater than 0.9 and InP/BghiP ratios of 0.7 in the soil. This finding confirmed that PAHs in soils of Nepal came from combustion of liquid fossil fuels. PC2 explained $29 \%$ of the total variance and had larger loadings on Pyr, Flu and BaA, while PC3 explained 23\% of the total variance and had larger loadings on Acy, Ace and Fl (Table 3 and Fig. 4). Since Pyr, Flu, Acy and Ace are key indicators of coal or wood combustion (Daisey et al., 1986; Harrison et al., 1996; Wilcke and Amelung, 2000), consumption of coal and biomass in Nepal could affect the soil PAH distributions. Given that the Nepalese population had similar living habits, customs and energy consumption, firewood is commonly used for heating in high altitude area (Bhatt and Sachan, 2004).

\subsection{Factors influencing the PAH distribution in soil}

\subsubsection{Wind}

Seasonal differences in direction of wind likely play a major role in atmospheric pollutant transport and deposition (Loewen et al., 2005). Since mean concentrations of LMW-PAHs in soils at each transect accounted for more than $80 \%$ of the total concentration of PAHs (Table 1), PAHs from the atmosphere were the main source of PAHs in soils. During the monsoon season, air masses from the Indian Ocean travelled over Bengal Bay, crossed some densely populated cities such as Calcutta, Patna, Varanasi, Kanpar and Lucknow on the plains of India and reached T1 (with a low mean altitude of $107 \pm 48 \mathrm{~m}$ ) from southeast Nepal (Fig. S1, Fig. 1B, Table 1). Consequently, the mean concentration of PAHs $(242 \pm 193 \mathrm{ng} / \mathrm{g}, \mathrm{dw})$ at T1 was greatest among those of the three transects and concentrations of PAHs in soils of T1 decreased from southeast to northwest (Table 1 and Fig. 1B). Part of the air masses from the plains of India continuously lift towards the north, passed over some urbanized regions in Nepal such as Pokhara and Kathmandu, accumulated local PAHs and brought them to T2 which had a higher mean altitude of $1680 \pm 640 \mathrm{~m}$, before they were intercepted by the southern side of the Himalayas (Fig. S1, Fig. 1B, Table 1). Because of less emission of atmospheric PAHs from Nepal compared to that from India and the decrease in atmospheric PAH concentration with increasing distance from its sources in India and Nepal, the mean concentration of PAHs at T2 decreased correspondingly. There was almost no local human activity near T3 which had the highest mean altitude of $4535 \pm 412 \mathrm{~m}$ among the three transects. Air masses reached T3 after passing many Himalayan mountain ranges (Fig. S1, Fig. 1B). The remarkably low mean concentration of PAHs, but the highest contribution of LMW-PAHs to total PAHs (92\%) in the soils of T3 (Table 1) indicate that the PAHs in the soils of T3 were most likely from long-range atmospheric transport of the monsoon, while the Himalayan Mountains acted as barriers restricting the movement of southeasterly monsoon air masses from the northern side of the Himalayas in Nepal (T2) to the southern side of the Himalayas in China (T3) (Fig. 1B and Fig. S1). Back-trajectories suggested that westerlies travelled over urban and industrialized regions in northern India (such as New Delhi and Chandigarh) and blew from the west to east. However, westerlies were blocked by the Himalayas and the Tibetan Plateau (Fig. S2). Because westerly air masses were depleted of PAHs over their long travel distance, compared to southerly air masses, westerly air masses brought less of the PAHs to the study area. However, local emissions of PAHs from northern India in winter still resulted in the somewhat gradual decreasing trends of concentrations of PAHs from the west to middle along transects (Fig. 1B).

\subsubsection{Altitude}

Altitude is another important factor that can influence the soil $\mathrm{PAH}$ distributions in the Himalayan Mountains (Guzzella et al., 2011). For the five soils selected from the NSHC, the concentrations of Phe, Flu and Acy were significantly and positively correlated with altitude (Fig. 3I-III). On the other hand, for the five soils selected from the SSHN, only the soil concentrations of Phe were significantly and positively correlated with altitude (Fig. 3IV). However, the concentrations of the other PAH individuals in the soils of Nepal and China exhibited no correlation with altitude (not shown here). However, the concentrations of total PAHs in soils from Nepal and China had significant linear correlations with altitude (Fig. 3V, VI). Presence of more volatile PAH individuals in high altitude areas in China than in low altitude areas in Nepal was correlated with altitude. Based on the results of a study by Shunthirasingham et al. (2013), the main source of soil PAHs in the mountains at high altitude was atmospheric deposition because the areas at altitudes above $3000 \mathrm{~m}$ in the Himalaya are largely unpopulated by people and are thought to be largely free of PAH pollution (Loewen et al., 2005). When PAH depositions result from long-distance atmospheric transport, soil concentrations of PAHs increased with increasing altitude (Daly et al., 2007). Our finding is also consistent with the observations of Miguel et al. (2004) and Wania and Mackay (1993), who noted that because LMW-PAHs attach more easily to finer aerosols, they are more likely to accumulate in high altitude areas. The altitudinal dependence of the concentrations of the more volatile compounds is also called the "cold trap effect" (Wania and Mackay, 1993; Wang et al., 2006). Greater precipitation in the NSHC, often in the form of snow, which is thought to be a very efficient scavenger of more volatile PAHs (Loewen et al., 2005; Guzzella et al., 2011), could provide a significant mechanism for the deposition of PAHs in soils in high altitude areas. One reason for the weak correlation between the concentrations of LMW-PAHs in the soils of Nepal and altitude is the fact that Nepal is more strongly influenced by the Indian monsoon and has a greater spatial variation of altitude and precipitation than the 
TPC. However, because HMW-PAHs are less volatile, generally less abundant in suspended aerosols, transported by air over short distances and influenced greatly by local human activities (Wania and Mackay, 1993; Guzzella et al., 2011), it is difficult to determine the complex relationships between their concentrations and the altitude on regional scales. Based on above observations, it is easy to conclude that the significant and positive relationships between $\Sigma_{16}$ PAH concentrations and altitude occurred in our study because concentrations of LMW-PAHs contributed more than 70\% to those of $\Sigma_{16} \mathrm{PAHs}$ in both China and Nepal (Table 1). This result was also supported by Wang et al. (2007) who suggested that concentrations of total and 3-ring PAHs in Himalayan soils were positively correlated with altitude $(4700-5600 \mathrm{~m})$, whereas no correlation was found for HMW-PAHs.

\subsubsection{Land use}

Besides deposition from the atmosphere, land use influences concentrations of PAHs and distributions in soils. Mean concentrations of $\Sigma_{16} \mathrm{PAHs}$ in the soils from different land uses on the NSHC decreased in the following order: farmlands $>$ grasslands $>$ forestlands. On the SSHN, the farmlands had the highest mean concentration of PAHs, followed by the forestlands (Fig. 1A and Table 4). As shown in Fig. 1A, most farmlands were located in valleys with low elevations, and they were close to cities and towns, where domestic heating and traffic occurred. Burning of biomass and emissions from vehicles accounted for a relatively large proportion of concentrations of PAHs in farmland soil from the TPC and Nepal. Burning of biomass accounted for $87 \%$ of the total energy requirements and produced $90 \%$ of total emissions of PAHs in Nepal and India (Zhang and Tao, 2009). Approximately two million tons of dung is burned annually in Tibet. However, lesser concentrations of oxygen, which were unfavourable for efficient biomass combustion, resulted in greater PAH emissions in mountain areas (Wang et al., 2014). Thus, burning of biomass might be the main reason for greater concentrations of PAHs in farmland soils. On the TPC, grasslands cover a greater area than forestlands (Fig. 1A). During summer when high alpine pastures were used for grazing, concentrations of PAHs in grassland soils were strongly influenced by human activities such as combustion of biomass for heating and cooking during grazing in more remote regions. However, the forestland area is very small and generally located far from intense anthropogenic activities on the TPC (Fig. 1A). Therefore, soils in grasslands had greater concentrations of PAHs than did forestlands on the NSHC. Large-scale vegetation of forest (Fig. 1A) and more human activities, such as industry, agriculture, traffic and tourism, as well as sometimes forest fires, in Nepal might have been responsible for the greater concentrations of PAHs in some forestlands on the SSHN. It has been reported that soil organic carbon (SOC) content is an important factor that determines the PAH concentrations in the soils of different land use, as SOC can significantly increase the sorption of PAHs to soil (Boehm et al., 2002). However, during the present study, soils in farmlands, which had the least content of SOC, had the greatest concentrations of PAHs, while the forestlands which

\section{Table 4}

Comparison of SOM, pH and concentrations of PAHs in different land uses on the northern and southern sides of the Himalayas between China and Nepal.

\begin{tabular}{llllll}
\hline & Land use & Sampling size & SOM $(\%)$ & $\mathrm{pH}$ & PAHs $(\mathrm{ng} / \mathrm{g}, \mathrm{dw})$ \\
\hline \multirow{2}{*}{ China } & Farm land & 10 & $17 \pm 10$ & $6.2 \pm 3.5$ & $191 \pm 106$ \\
& Grass land & 9 & $22 \pm 16$ & $6.8 \pm 3.2$ & $127 \pm 63$ \\
\multirow{4}{*}{ Nepal } & Forest land & 8 & $86 \pm 53$ & $7.2 \pm 2.7$ & $107 \pm 96$ \\
& Farm land & 20 & $11 \pm 7$ & $5.1 \pm 3.3$ & $334 \pm 207$ \\
& Forest land & 30 & $17 \pm 13$ & $5.3 \pm 4.1$ & $268 \pm 248$ \\
\hline
\end{tabular}

had the greatest content of SOC had the least concentrations of PAHs. Differential degradation of PAHs in soil might partly explain this result. It has been reported that addition of farmyard manure to farmland might cause stronger sorption of PAHs and thus inhibit degradation and leaching (Beck et al., 1996). Perhaps, the poor correlation between SOC and PAHs in our study may be that, as reported by Simpson et al. (1996), the soil PAH concentrations in this study did not exceeded $2000 \mathrm{ng} / \mathrm{g}$, dw. Results of other studies have suggested that $\mathrm{pH}$ influences the distribution of PAHs in soils. For example, a pH above 6.5 was best for degrading PAHs, and a more alkaline $\mathrm{pH}$ was capable of promoting the downward movement of PAHs in the soil (Pawar, 2012). Since the forestland soil was more alkaline $(\mathrm{pH}=7.2)$ than the grassland soil $(\mathrm{pH}=6.8)$ on the NSHC (Table 4), the forestlands had a lower mean concentration of $\Sigma_{16}$ PAHs than the grasslands. The fact that the farmlands on the SSHN had lower mean $\mathrm{pH}$ values $(\mathrm{pH}=5.0)$ but higher $\Sigma_{16} \mathrm{PAH}$ concentrations than those on the NSHC $(\mathrm{pH}=6.5)$ also indicated that low $\mathrm{pH}$ values prevent PAHs from moving downward through the soil. Consequently, the farmlands had the mean concentration of $\Sigma_{16} \mathrm{PAHs}$ greater than the forestlands and grasslands.

\section{Conclusions}

The mean concentration of $\Sigma_{16} \mathrm{PAHs}$ in soils from the NSHC was $126 \pm 83 \mathrm{ng} / \mathrm{g}$, dw which was greater than the background concentration in soils of the TPC and those previously reported in eastern, middle, western and north-western Tibetan Plateau on the NSHC. The mean concentration of $\Sigma_{16}$ PAHs in soils from the SSHN was $190 \pm 192 \mathrm{ng} / \mathrm{g}$, dw, which was significantly less than those from areas with intense human activities in Nepal and India. Concentrations of $\Sigma 2-3$-ring PAHs, especially Acy and Phe/Fl, in soils from two sides of the Himalayas accounted for more than $87 \%$ of their total PAHs. The mean concentration of PAHs in soils from the SSHN was significantly greater than that in soils from the NSHC. Thirty-two percent of soil samples from the SSHN and $22 \%$ of soil samples from the NSHC were weakly contaminated by PAHs. Relatively great concentrations of PAHs (200-400 ng/g, dw) were observed near Shigatse, Lhaze, Dingri, Nyemo, especially the port of Zhangmu, in the east and middle regions on the NSHC and Kathmandu, Pokhara, Birgunj and Janakpur in the central and eastern Nepal. Emissions from traffic and combustion of coal or biomass were the major sources of PAHs in the soils from the study area. Based on backward projections of trajectories of air masses, the Indian monsoon significantly affected spatial distribution of PAH individuals in soils. PAHs with 2-3 rings can easily be transported long distances and deposited into soils. The Himalayan Mountains acted as barriers restricting south-easterly monsoon air masses from moving from the northern side of the Himalayas in Nepal to the southern side of the Himalayas in China. However, westerlies from northern India had very limited effects on the soil concentrations of PAHs. Presence of more volatile PAH individuals in high altitude areas in China than in low altitude areas in Nepal was correlated with altitude. Mean concentrations of $\Sigma_{16}$ PAHs in the soils are in the order: farmlands $>$ grasslands $>$ forestlands in the study area.

\section{Acknowledgements}

This study was supported by the Strategic Priority Research Program of the Chinese Academy of Sciences (grant No. XDB03030504), the National Natural Science Foundation of China (grant Nos. 41271502 and 41420104004), and the International Scientific Cooperation Program (grant No. 2012DFA91150). Prof. Giesy was supported by the 2014 "High Level Foreign Experts" (\#GDT20143200016) program funded by the State Administration 
of Foreign Experts Affairs, P. R. China, to Nanjing University and the Einstein Professor Program of the Chinese Academy of Sciences. He was also supported by the Canada Research Chair program, a Visiting Distinguished Professorship in the Department of Biology and Chemistry, and the State Key Laboratory in Marine Pollution, City University of Hong Kong.

\section{Appendix A. Supplementary data}

Supplementary data related to this article can be found at http:// dx.doi.org/10.1016/j.envpol.2015.11.018.

\section{References}

Aichner, B., Glaser, B., Zech, W., 2007. Polycyclic aromatic hydrocarbons and polychlorinated biphenyls in urban soils from Kathmandu, Nepal. Org. Geochem. 38, 700-715.

Beck, A.J., Johnson, D.L., Jones, K.C., 1996. The form and bioavailability of non-ionic organic chemicals in sewage sludge-amended agricultural soils. Sci. Total Environ. 185, 125-149.

Bhatt, B.P., Sachan, M.S., 2004. Firewood consumption along an altitudinal gradient in mountain villages of India. Biomass \& Bioenergy 27, 69-75.

Boehm, P.D., Burns, W.A., Page, D.S., Bence, A.E., Mankiewicz, P.J., Brown, J.S., Douglas, G.S., 2002. Total organic carbon, an important tool in a holistic approach to hydrocarbon source fingerprinting. Environ. Forensics 3, 243-250.

Choi, S.D., Shunthirasingham, C., Daly, G.L., Xiao, H., Lei, Y.D., Wania, F., 2009. Levels of polycyclic aromatic hydrocarbons in Canadian mountain air and soil are controlled by proximity to roads. Environ. Pollut. 157, 3199-3206.

Dachs, J., Bayona, J.M., Ittekkot, V., Albaiges, J., 1999. Monsoon-driven vertical fluxes of organic pollutants in the western Arabian Sea. Environ. Sci. Technol. 33, 3949-3956.

Daisey, J.M., Cheney, J.L., Lioy, P.J., 1986. Profiles of organic particulate-emissions from air-pollution sources-status and needs for receptor source apportionment modeling. J. Air Pollut. Control Assoc. 36, 17-33.

Daly, G.L., Lei, Y.D., Castillo, L.E., Muir, D.C.G., Wania, F., 2007. Polycyclic aromatic hydrocarbons in Costa Rican air and soil: a tropical/temperate comparison. Atmos. Environ. 41, 7339-7350.

Elliott, J.E., Levac, J., Guigueno, M.F., Shaw, D.P., Wayland, M., Morrissey, C.A., Muir, D.C.G., Elliott, K.H., 2012. Factors influencing legacy pollutant accumulation in alpine osprey: biology, topography, or melting glaciers? Environ. Sci. Technol. 46, 9681-9689.

Grimalt, J.O., van Drooge, B.L., Ribes, A., Fernández, P., Appleby, P., 2004. Polycyclic aromatic hydrocarbon composition in soils and sediments of high altitude lakes. Environ. Pollut. 131 (1), 13-24.

Guzzella, L., Poma, G., De Paolis, A., Roscioli, C., Viviano, G., 2011. Organic persistent toxic substances in soils, waters and sediments along an altitudinal gradient at Mt. Sagarmatha, Himalayas, Nepal. Environ. Pollut. 159, 2552-2564.

Harrison, R.M., Smith, D.J.T., Luhana, L., 1996. Source apportionment of atmospheric polycyclic aromatic hydrocarbons collected from an urban location in Birmingham, UK. Environ. Sci. Technol. 30, 825-832.

Kang, J.H., Choi, S.D., Park, H., Baek, S.Y., Hong, S., Chang, Y.S., 2009. Atmospheric deposition of persistent organic pollutants to the east Rongbuk glacier in the Himalayas. Sci. Total Environ. 408, 57-63.

Kumar, B., Verma, V.K., Kumar, S., Sharma, C.S., 2013. Probabilistic health risk assessment of polycyclic aromatic hydrocarbons and polychlorinated biphenyls in urban soils from a tropical city of India. J. Environ. Sci. Health Part A-Toxic/ Hazardous Subst. Environ. Eng. 48, 1253-1263.

Loewen, M.D., Sharma, S., Tomy, G., Wang, F., Bullock, P., Wania, F., 2005. Persistent organic pollutants and mercury in the Himalaya. Aquat. Ecosyst. Health 8, 223-233.

Maliszewska-Kordybach, B., 1996. Polycyclic aromatic hydrocarbons in agricultural soils in Poland: preliminary proposals for criteria to evaluate the level of soil contamination. Appl. Geochem. 11, 121-127.

Masclet, P., Mouvier, G., Nikolaou, K., 1986. Relative decay index and sources of polycyclic aromatic-hydrocarbons. Atmos. Environ. 20, 439-446.

Masih, A., Taneja, A., 2006. Polycyclic aromatic hydrocarbons (PAHs) concentrations and related carcinogenic potencies in soil at a semi-arid region of India. Chemosphere 65, 449-456.

Miguel, A.H., Eiguren-Fernandez, A., Jaques, P.A., Froines, J.R., Grant, B.L., Mayo, P.R., Sioutas, C., 2004. Seasonal variation of the particle size distribution of polycyclic aromatic hydrocarbons and of major aerosol species in Claremont, California. Atmos. Environ. 38, 3241-3251.

Nakata, H., Uehara, K., Goto, Y., Fukumura, M., Shimasaki, H., Takikawa, K., Miyawaki, T., 2014. Polycyclic aromatic hydrocarbons in oysters and sediments from the Yatsushiro Sea, Japan: comparison of potential risks among PAHs, dioxins and dioxin-like compounds in benthic organisms. Ecotoxicol. Environ. Saf. 99, 61-68.

Pawar, R.M., 2012. The Effect of Soil pH on Degradation of Polycyclic Aromatic Hydrocarbons (PAHs), School of Life Sciences. University of Hertfordshire.

Qi, S.H., Zhang, G., Liu, J.H., Zhang, W.L., 2003. Polycyclic aromatic hydrocarbons (PAHs) and its resources in Lhalu wetland, an urban wetland, in Lhasa city, China. In: Proceeding of International Symposium on Water Resources and the Urban Environment, pp. 253-256.

Quiroz, R., Grimalt, J.O., Fernandez, P., Camarero, L., Catalan, J., Stuchlik, E., Thies, H., Nickus, U., 2011. Polycyclic aromatic hydrocarbons in soils from European high mountain areas. Water, Air, \& Soil Pollut. 215, 655-666.

Ray, S., Khillare, P.S., Kim, K.H., Brown, R.J., 2012. Distribution, sources, and association of polycyclic aromatic hydrocarbons, black carbon, and total organic carbon in size-segregated soil samples along a background-urban-rural transect. Environ. Eng. Sci. 29, 1008-1019.

Shunthirasingham, C., Wania, F., MacLeod, M., Lei, Y.D., Quinn, C.L., Zhang, X.M., Scheringer, M., Wegmann, F., Hungerbuhler, K., Ivemeyer, S., Heil, F., Klocke, P. Pacepavicius, G., Alaee, M., 2013. Mountain cold-trapping increases transfer of persistent organic pollutants from atmosphere to cows' milk. Environ. Sci. Technol. 47, 9175-9181.

Simpson, C.D., Mosi, A.A., Cullen, W.R., Reimer, K.J., 1996. Composition and distribution of polycyclic aromatic hydrocarbon contamination in surficial marine sediments from Kitimat Harbor, Canada. Sci. Total Environ. 181, 265-278.

Tao, S., Wang, W., Liu, W., Zuo, Q., Wang, X., Wang, R., Wang, B., Shen, G., Yang, Y., He, J.S., 2011. Polycyclic aromatic hydrocarbons and organochlorine pesticides in surface soils from the Qinghai-Tibetan Plateau. J. Environ. Monit. 13 (1), $175-181$.

Tremolada, P., Villa, S., Bazzarin, P., Bizzotto, E., Comolli, R., Vighi, M., 2008. POPs in mountain soils from the Alps and Andes: suggestions for a 'precipitation effect' on altitudinal gradients. Water, Air, \& Soil Pollut. 188, 93-109.

van Drooge, B.L., Lopez, J., Fernandez, P., Grimalt, J.O., Stuchlik, E., 2011. Polycyclic aromatic hydrocarbons in lake sediments from the High Tatras. Environ. Pollut. 159, 1234-1240.

Wang, C., Wang, X.P., Gong, P., Yao, T., 2014. Polycyclic aromatic hydrocarbons in surface soil across the Tibetan Plateau: spatial distribution, source and air-soil exchange. Environ. Pollut. (Barking, Essex 1987) 184, 138-144.

Wang, S., Ni, H.G., Sun, J.L., Jing, X., He, J.S., Zeng, H., 2013. Polycyclic aromatic hydrocarbons in soils from the Tibetan Plateau, China: distribution and influence of environmental factors. Environ. Science-Processes Impacts 15 (3), 661-667.

Wang, X.P., Gong, P., Yao, T.D., 2008. Progress about the research of atmospheric persistent organic pollutants in remote areas. Environ. Sci. 29 (2), 2273-2282 (in Chinese).

Wang, X.P., Yao, T.D., Cong, Z.Y., Yan, X.L., Kang, S.C., Zhang, Y., 2006. Gradient distribution of persistent organic contaminants along northern slope of centralHimalayas, China. Sci. Total Environ. 372, 193-202.

Wang, X.P., Yao, T.D., Cong, Z.Y., Yan, X.L., Kang, S.C., Zhang, Y., 2007. Concentration level and distribution of polycyclic aromatic hydrocarbons in soil and grass around Mt. Qomolangma, China. Chin. Sci. Bull. 52, 1405-1413.

Wang, X.P., Gong, P., Yao, T.D., Jones, K.C., 2010. Passive atmospheric sampling of organochlorine pesticides, polychlorinated biphenyls, and polybrominated diphenyl ethers across the Tibetan Plateau. Environ. Sci. Technol. 44, 2988-2993.

Wania, F., Mackay, D., 1993. Global fractiontion and cold condensation of low volatility organochlorine compounds in polar-regions. Ambio 22, 10-18.

Wania, F., Mackay, D., 1996. Tracking the distribution of persistent organic pollutants. Environ. Sci. Technol. 30, A390-A396.

Weiss, P., Lorbeer, G., Scharf, S., 2000. Regional aspects and statistical characterisation of the load with semivolatile organic compounds at remote Austrian forest sites. Chemosphere 40 (9-11), 1159-1171.

Wilcke, W., Amelung, W., 2000. Persistent organic pollutants in native grassland soils along a climosequence in North America. Soil Sci. Soc. Am. J. 64 $2140-2148$.

Yang, R.Q., Zhang, S.J., Li, A., Jiang, G.B., Jing, C.Y., 2013. Altitudinal and spatial signature of persistent organic pollutants in soil, lichen, conifer needles, and bark of the Southeast Tibetan Plateau: implications for sources and environmental cycling. Environ. Sci. Technol. 47, 12736-12743.

Yuan, G.L., Qin, J.X., Li, J., Lang, X.X., Wang, G.H., 2014. Persistent organic pollutants in soil near the Changwengluozha glacier of the Central Tibetan Plateau, China: their sorption to clays and implication. Sci. Total Environ. 472, 309-315.

Yuan, G.L., Wu, L.J., Sun, Y., Li, J., Li, C.J., Wang, G.H., 2015. Polycyclic aromatic hydrocarbons in soils of the central Tibetan Plateau, China: distribution, sources, transport and contribution in global cycling. Environ. Pollut. 203, 137-144.

Yunker, M.B., Macdonald, R.W., Vingarzan, R., Mitchell, R.H., Goyette, D., Sylvestre, S., 2002. PAHs in the Fraser River basin: a critical appraisal of PAH ratios as indicators of PAH source and composition. Org. Geochem. 33 (4), 489-515.

Zhang, Y., Tao, S., 2009. Global atmospheric emission inventory of polycyclic aromatic hydrocarbons (PAHs) for 2004. Atmos. Environ. 43, 812-819. 